\title{
ANALYSIS OF STATIC ANGLE OF REPOSE WITH RESPECT TO POWDER MATERIAL PROPERTIES
}

\author{
Oliver Macho $^{a, *}$, Karin Demková ${ }^{b}$, Ludumlla Gabrišová $^{a}$, \\ Matúš Čierny ${ }^{a}$, Jitka Mužíková ${ }^{c}$, Paulína Galbavá ${ }^{d}$, Žofia Nižnanskád, \\ Jaroslav BlašKo ${ }^{d}$, Peter Peciar ${ }^{a}$, Roman FeKete ${ }^{a}$, Marián Peciar ${ }^{a}$ \\ a Slovak University of Technology in Bratislava, Faculty of Mechanical Engineering, Institute of Process \\ Engineering, Námestie Slobody 17, 81231 Bratislava, Slovakia \\ ${ }^{b}$ High School of Jur Hronec, Novohradská 3, 82109 Bratislava, Slovakia \\ ${ }^{c}$ Charles University, Faculty of Pharmacy, Department of Pharmaceutical Technology, Ak. Heyrovského 1203, \\ 50005 Hradec Králové, Czech Republic \\ ${ }^{d}$ Comenius University in Bratislava, Faculty of Natural Sciences, Institute of Chemistry, Ilkovičova 6 - Mlynská \\ dolina, 842 15 Bratislava, Slovakia \\ * corresponding author: oliver.macho@stuba.sk
}

\begin{abstract}
This paper investigates the Angle of Repose $(A o R)$ of powder materials with respect to their morphological and rheological properties. Glass beads, sand, flour and semolina of different particle sizes were used as the experimental materials. The investigated material was analysed with respect to particle shape and size. The rheological properties of the material were obtained by a shear cell test. The $A o R$ was analysed in terms of cohesion, bulk density, particle size and circularity. More cohesive materials such as the flour samples exhibited the largest $A o R>40^{\circ}$, indicating their poor flowability. Glass bead samples with a high circularity value had significantly lower $A o R$ than the flour. The Angle of Internal Friction values were not dependent on those of the AoR. Using a dimensional analysis, a mathematical model was developed to determine the $A o R$ values based on the material properties. By the application of this model, highly accurate calculation of the value of $A o R$ is made possible.
\end{abstract}

KEYwORDS: Angle of repose, cohesion, powders, angle of internal friction, bulk density.

\section{INTRODUCTION}

Investigation of the flow properties of powder or granular materials is a key area for the correct design of equipment working with such material types. Powder flowability means the capacity of a powder to flow under a specified set of conditions [1]. There are several techniques to determine flowability. However, a single reliable and widely applicable method of measuring of flowability does not exist, because of the variety of both powder materials and the influence of handling on the measurement results [2]. One of the methods for quickly determining the nature of this flow is the measurement of the Angle of Repose $(A o R)$. The $A o R$ measurement is used in many applications of processing, storing and handling powder materials, determining the slope stability, furnace design and many other uses. Physically, the $A o R$ can be defined as the angle that differentiates the transitions between phases of a granular material. One of the most commonly used definitions of the $A o R$ is the steepest slope of an unconfined material, measured from the horizontal plane on which the material can be heaped without collapsing [3]. This angle is also sometimes referred to as the critical slope angle or friction angle. Measuring the $A o R$ has a wide area of application, ranging from pharmaceutical through chemical, agricultural, mining engineering and geology to civil engineering uses [4]. The two basic types of the $A o R$ are static and dynamic 5]. The static $A o R$ is determined by using an experimental apparatus with a funnel-defined geometry through which the experimental material is poured. The falling material is collected on a defined circular pad under the funnel (fixed-base) or is loosely poured onto a plate (free-base) with the individual layers of material forming a steep pile (cone) [6]. The dynamic angle is determined by a rotating drum in which the material under investigation is reformed by the effect of rotation as by an avalanche. By measuring the slope of the moving powder from the center of the experimental station, we obtain the Avalanche Angle [7. Among modern trends in the measurement of the $A o R$ are the following techniques: 3D scanning of created piles [8, 9], or modeling by the discrete element method [10 12. Flow properties of powders present a complex characteristic of a bulk powder, and they are affected by physico-chemical and mechanical properties of the particles [13]. The interaction forces of the powder consist of Van der Waals forces, capillary forces, electrostatic forces of the powders, and similar [14]. Moreover, the size, shape and material surface elasticity are also dominant factors. Several authors have devoted their $A o R$ research to materials 


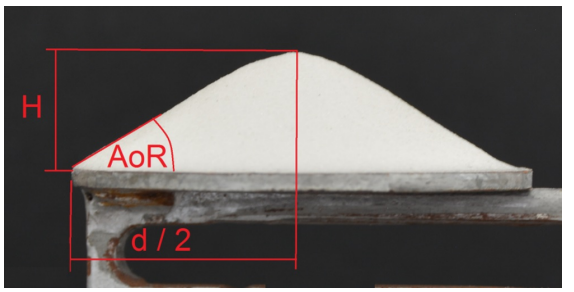

Figure 1. Scheme of measurement of $A o R$ (Fine glass bead particles).

with different material properties, such as aluminum powder [15], corn grains, lignite, wood chips [16], asphalt concrete [17, rice and flours [18, pulverized coal [19], iron ore [20, biomass [21], sugar 22] or fine dust from power plants 23 . The aim of this study was to analyse the impact of rheological and morphological properties of selected materials and their effect on the $A o R$ size. In this paper, we investigated the static AoR obtained from measurements on an experimental station using the fixed-base method. Using dimensional analysis, a mathematical model was developed to determine the $A o R$ values based on the material properties of the experimental samples. By an application of this model, it is posssible to calculate the value of static $A o R$ with a high accuracy.

\section{MATERIAL AND METHODS}

\subsection{EXPERIMENTAL MATERIAL}

Two types of sand and semolina with different particle sizes were used as experimental coarse-grained materials. The sand was delivered in size intervals, coarse $(1.0-1.6 \mathrm{~mm})$ and finer $(0.8-1.2 \mathrm{~mm})$. Another material samples were five types of glass beads, from fine to approximately $0.5 \mathrm{~mm}$ in size. Cohesive materials were represented by flour with different fractions (Strong, Soft flour). The bulk density (BD) of the material was determined by means of a measuring cylinder into which $100 \mathrm{ml}$ of material was loaded. The BD value was determined from a known sample volume and weight, with the experiments repeated three times.

\subsection{MeAsurement of ANGLE of RePose}

The Static AoR measurement ran in an accordance with European Pharmacopoeia 9.0 (2.9.36) according to ASTM recommendations (C1444-00). The experimental material was poured through a funnel of diameter $\mathrm{D}=10 \mathrm{~mm}$ onto a pad of diameter $\mathrm{d}=50 \mathrm{~mm}$ until a cone was formed which did not change shape with a continued pouring. The excess material fell over the edge of the pad. Static AoR measurements were performed 3 times for each material. AoR values were obtained by the analysis of individual measurements (Fig. 1) and calculated according to the relationship (1).

$$
A o R=\arctan \left[\frac{H}{d / 2}\right]
$$

where $H$ is the height of the cone and $d$ is the diameter of the pad.

\subsection{Morphology of EXPERIMENTAL POWDRES}

The size and shape of the particles were analysed using a Morphologi G3 (Malvern) optical microscope. Samples of the material were evaluated based on the volume of the individual particles. The characteristic particle size marker was the median of Circle Equivalent $(C E)$. $C E$ represents the diameter of a circular particle with the same volume as the particle under the investigation. The particle shape was evaluated using Circularity $\Phi$. The higher the value, the more circular the particles examined: $\Phi=1$ corresponds perfectly to circular particles.

\subsection{Powders RHEOLOGY}

Using a FT4 (Freeman Technology) powder rheometer based on ASTM-D6773-16 [24], individual samples were analysed from the rheological point of view. Using the Shear Cell Test (sample consolidation $9 \mathrm{kPa}$ ), the cohesion $(c)$ and the angle of internal friction $(A I F)$ were determined. The experiments were repeated three times for each material. The pre-shear value was $9 \mathrm{kPa}$ and the shear head produced normal stresses of $7,6,5,4$ and $3 \mathrm{kPa}$ in the materials, and the corresponding shear stresses were recorded for the individual values of the normal stresses. From the normal and shear stress points a yield locus was created. The Angle of internal friction is the tangent of the linearized yield locus 25. The higher the $A I F$ value, the smaller the interparticular forces, and the more flowable the powder. Cohesion represents the degree of coherence of the test substance. Its value is influenced by interparticle forces (van der Walls), material moisture, particle size and others. The more cohesive the material, the worse flow properties and lower the $f f_{c}$ flow function parameter [26].

\subsection{Evolution OF ANGLE OF REPOSE IN TIME}

The increase of the $A o R$ over time was determined by an image analysis of the videos captured by a tripod-mounted Nikon D5500 digital camera. The created videos were transformed into static images representing defined times of the pouring. ImageJ software was used to analyse the pile growth over time [27. The dimensions and shape of the piles were then transformed from pixels to centimeters using a scale. In these experiments, semolina was used as the experimental material. Shape and pile size were examined by pouring the material onto a horizontal base from a height of $14 \mathrm{~cm}$ depending on different pouring times. The material was poured through 5 and $8 \mathrm{~mm}$ diameter drain holes of funnels. 


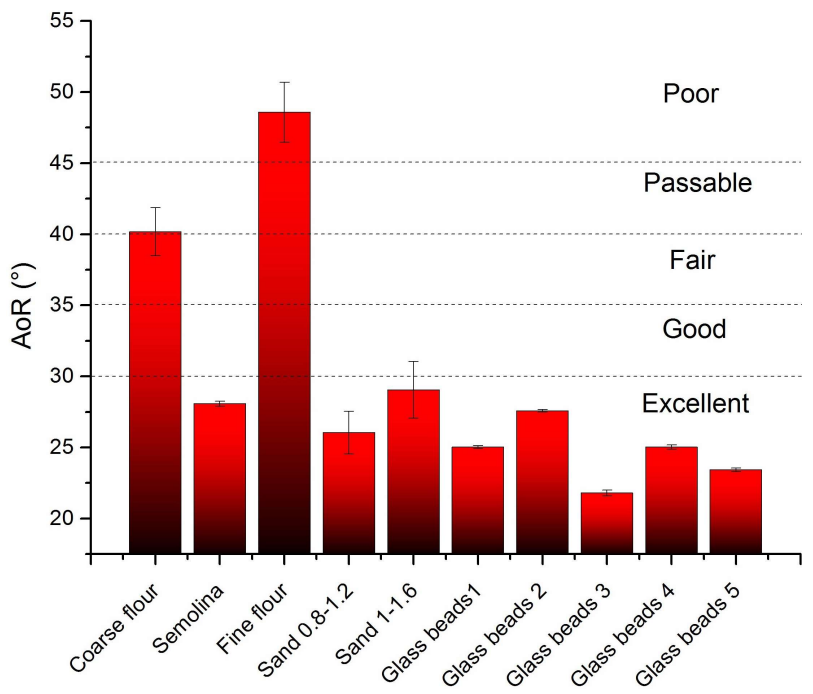

Figure 2. Values of $A o R$ for different experimental material.

\section{Results AND Discussion}

\subsection{ANGLe OF REPOSE}

Fig. 2 shows the values of the $A o R$. Based on the values of the $A o R$, the flow properties of the examined material can be established 28 . The graph shows the highest value of the $A o R$ was found with soft flour $A o R=48.58 \pm 2.1^{\circ}$. This value corresponds to poor flow properties. The second worst flow properties were observed in strong flour $A o R=40.18 \pm 1.7^{\circ}$, on the border of passable and fair flow properties. Semolina and glass beads, materials with the largest particles, have excelent flow properties based on the AoR $\left(A o R<30^{\circ}\right)$. Experimental data can be found in Tab. 1

\subsection{Particle morphology AND BUlK DENSITY}

Individual material properties were analysed based on their effect on the $A o R$ value. Coarse sand had lower $A o R$ values than fine flour particles (Fig. 3). The median particle size values of the coarse and fine sand were $C E=1459 \mu \mathrm{m}$ and $C E=1044 \mu \mathrm{m}$ respectively. For glass beads of increasing $C E$ values, the $A o R$ decreased with the exception of glass beads 4 . The finer flour has a bigger $A o R$ than strong flour. For sand materials, a greater value was observed for sand of the interval $1-1.6 \mathrm{~mm}$.

The circularity value (Fig. (4) was higher for sand particles ranging between $0.8-1.2 \mathrm{~mm}(\Phi=0.96)$ than for the sand particles between $1-1.6 \mathrm{~mm}$ $(\Phi=0.88)$. On the base of this finding, it could be said that the smaller particles with higher $\Phi$ have better flow properties than the particles with a higher $C E$. Similar examples are shown in study [29] with mannitol particles. Sphericity values decreased minimally as the size of the glass beads increased. All circular glass bead particles of $\Phi>0.99$ featured an

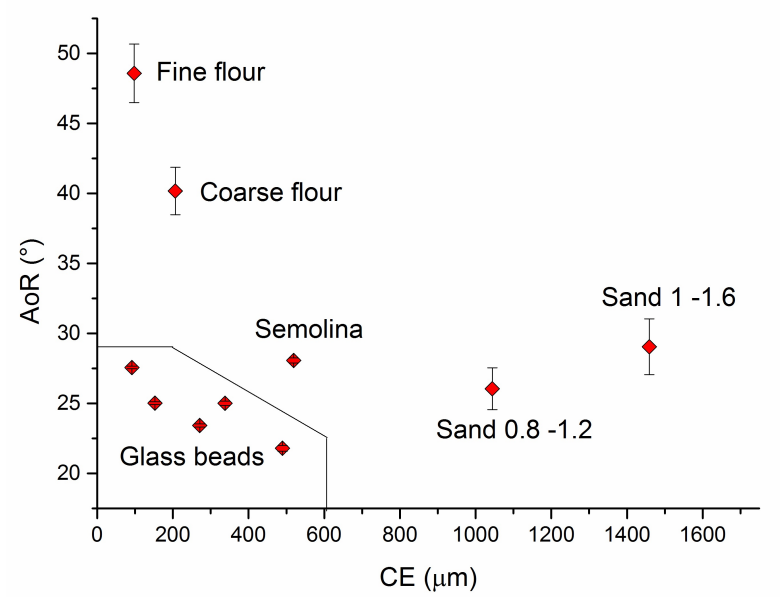

Figure 3. Influence of particle size $(C E)$ on $A o R$.

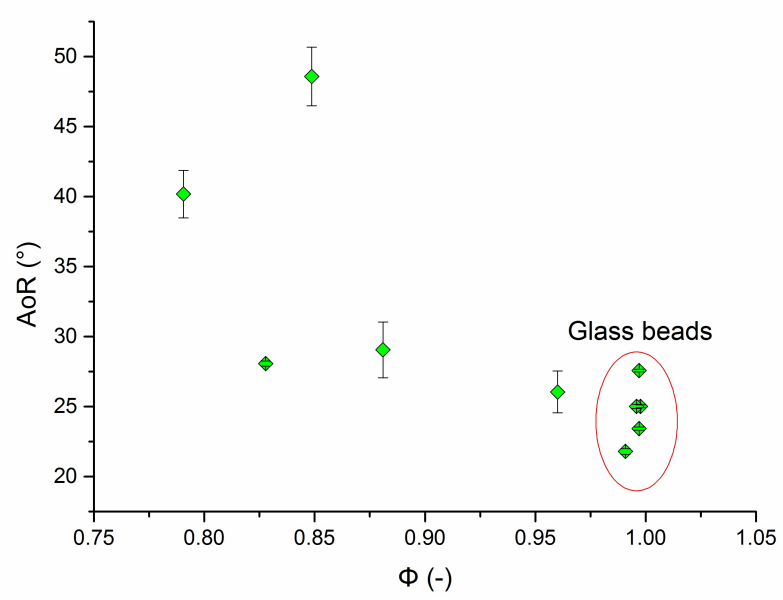

Figure 4. Influence of circularity $(\Phi)$ on $A o R$.

$A o R$ value of $24 \pm 3^{\circ}$, for all size fractions. Strong flour particles had the lowest value of circularity $(\Phi=0.79)$.

\subsection{Evaluation of BulK DENSity}

Bulk densities of the samples were $B D>1400 \mathrm{~kg} \cdot \mathrm{m}^{-3}$ for most materials (Fig. 5), with the maximum value of standard deviations being $0.02 \mathrm{~kg} \cdot \mathrm{m}^{-3}$. The sand particles in the $0.8-1.2$ range had the highest value of bulk density $1.63 \pm 0.02 \mathrm{~kg} \cdot \mathrm{m}^{-3}$ and the soft flour particles had the lowest bulk density $\left(0.632 \pm 0.003 \mathrm{~kg} \cdot \mathrm{m}^{-3}\right)$. The dynamic effect of falling particles of materials with higher BD values impacting on the substrate did not allow the formation of stiff cones on the pad. Due to the fact that self-weight particles tends to roll over an existing heap, move away and reach a stable state far away from the point of the fall. Except for semolina, samples with a lower $\mathrm{BD}$ value had values of the $A o R$ higher than $40^{\circ}$. Semolina particles had a significantly larger particle size of $C E=519.3 \mu \mathrm{m}$ compared to flour samples. 


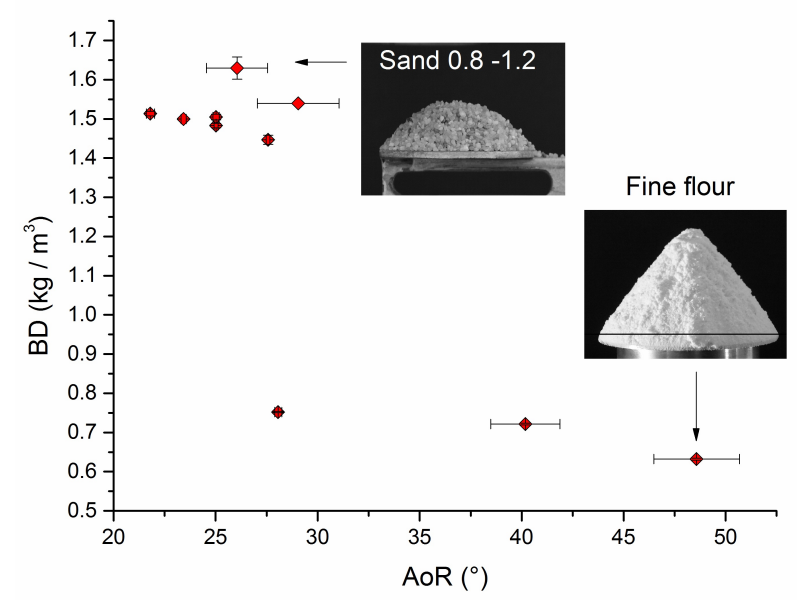

FiguRE 5. Influence of bulk density $(B D)$ on $A o R$.

\subsection{Evaluation of Particle Rheology}

The parameters describing the flowability of the powder can be determined from the yield locus. In order to measure the course of yield locus, several of the tests must be performed, where the specimens must first be consolidated at identical normal stress, preshear. Then, the specimens are sheared to failure, under different normal stresses. The yield locus follows from a plotted curve through all measured shear points. In Fig. 6] a graph of the Shear Cell Test from the FT4 rheometer for sands, flours and semolina is presented. Sand particles have a significantly steeper trend, which means they also have higher $A I F$ values. Significant deviations in the individual experiments were observed with the flour particles. The glass beads had values of $A I F<26^{\circ}$ in all cases. Fig. 7 shows the graph from the Shear Cell Test of glass beads. If the glass beads have a higher $C E$, then the yield locus line is significantly steeper, which implies a higher $A I F$ value. With an increasing glass bead particle size, the value of $A I F$ increased proportionally. For experiments with the glass bead particles significantly smaller deviations were observed.

From the cohesion impact on the AoR graph (Fig. 8), materials with a higher value of cohesion and, at the same time, the smallest $A I F$ achieved the highest $A o R$ values. The trend of the graph confirms the assumption that the greater the influence of interparticle forces, expressed by means of cohesion, the more coherent is the material, allowing the formation of a steeper pile. The most cohesive were the soft flour particles, where $c=1.597 \pm 0.23 \mathrm{kPa}$. For the glass bead particles, the value of cohesion for all types of the material was $c<0.25 \mathrm{kPa}$. The measurement of the cohesion confirmed that it had a significant effect on the flow properties of the examined materials, as well as the $A o R$ size.

Based on the graph (Fig. 9), it is possible to say that there is no direct relationship between the $A o R$ with load-free materials and the $A I F$ angle, which expresses the friction between the particles when an

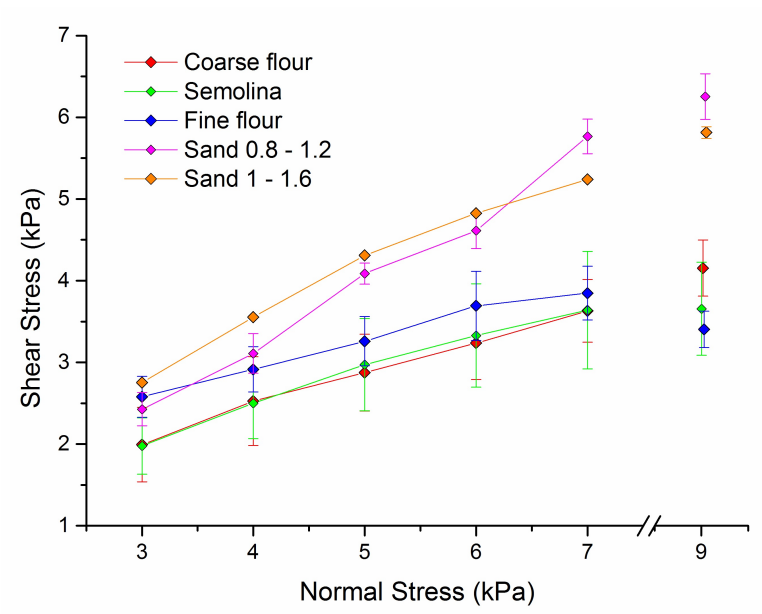

Figure 6. Shear Cell Test of sands, flours and semolina.

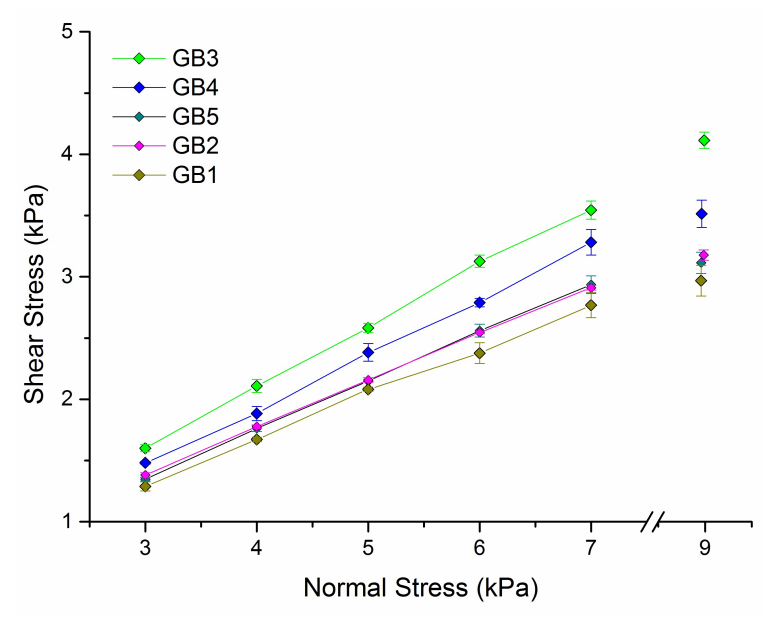

Figure 7. Shear Cell Test of glass beads particles.

external load is applied. A similar finding was published in a paper [4]. For flour samples, the $A I F$ was on average $20^{\circ}$ lower than the $A o R$, while the sand samples had a higher $A I F$ value. The $A I F$ values for glass beads were accompanied by minor deviations. The highest value of $A I F$ was found for $0.8-1.2 \mathrm{~mm}$ sand, $A I F=36.75 \pm 2.9^{\circ}$.

Fig. 10 shows a graphical dependence between cohesion and the $f f_{c}$ flow function parameter. The graph shows that these two parameters are power dependent. As shown by the higher cohesion value, the flow properties of the powder materials, whether expressed by $A o R$ or $f f_{c}$, are impaired.

\subsection{AoR IN TIME}

In Fig. 11, 12, graphical dependences of the growth of the pile when the semolina was poured onto a horizontal base from a height of $14 \mathrm{~cm}$ is shown. On the basis of the Baverloo equation, the discharge velocity of the semolina particles was calculated, for a funnel with a $5 \mathrm{~mm}$ outlet being $0.002081 \mathrm{~g} / \mathrm{s}$ and for an $8 \mathrm{~mm}$ outlet funnel being $0.007134 \mathrm{~g} / \mathrm{s}$. For an $8 \mathrm{~mm}$ funnel, 


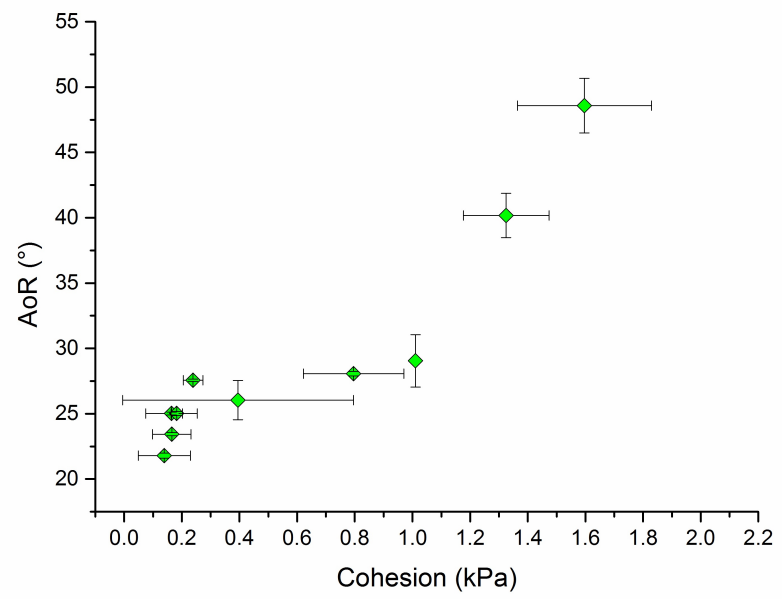

FiguRE 8. Influence of cohesion (c) on AoR.

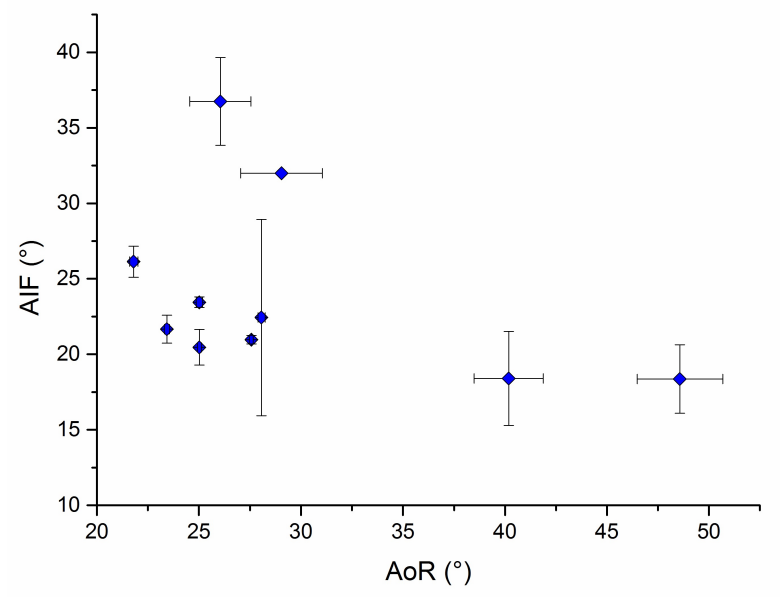

Figure 9. Comparison between Angle of Internal friction $(A I F)$ and $A o R$.

due to its larger cross-sectional area and therefore higher discharge speed, the flow time of the material was shorter. In both cases, the final shape of the pile began to form after $13 \mathrm{~s}$. At a lower discharge velocity, the pile reached a height of $4.86 \mathrm{~cm}$, and at a higher velocity, it reached a height of $4.65 \mathrm{~cm}$. The higher discharge velocity caused that the dynamic effect of a larger amount of falling particles did not allow the formation of a higher pile. Particles falling at higher discharge velocities tend to roll over existing heap.

\subsection{MODEL DESCRIPTION}

The dimensional analysis method was chosen to create the $A o R$ related model and the material properties obtained from the experiments. In relation (2), the same quantity $\left(^{\circ}\right)$ is present on both sides. The values of the individual material properties used for modeling were obtained as average values from repeating measurements.

$$
A o R=\frac{c \cdot \Phi \cdot A I F}{C E \cdot g \cdot B D}
$$

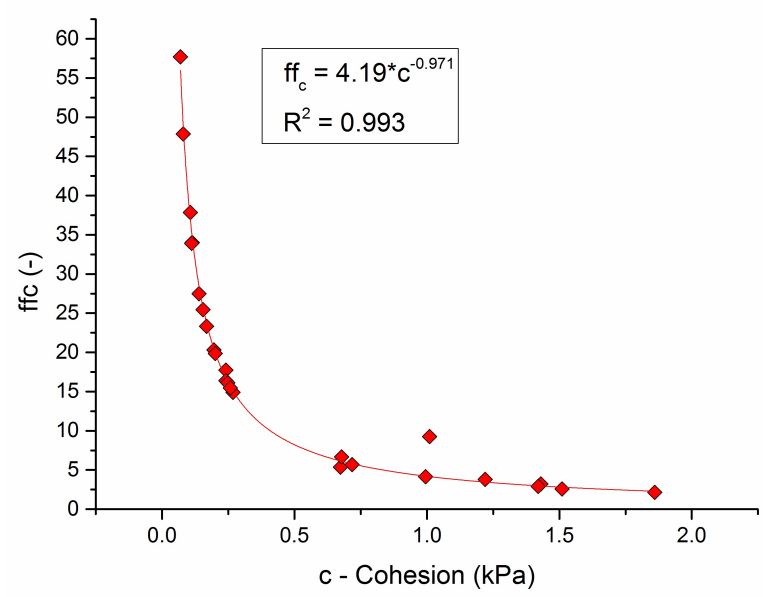

FiguRE 10. Influence of cohesion on flow function parameter.

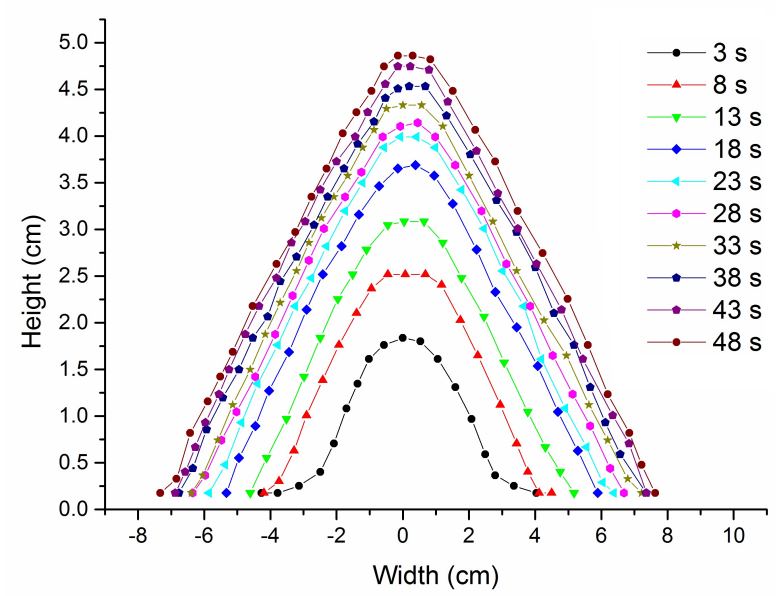

Figure 11. Evolution of $A o R$ during tests with $5 \mathrm{~mm}$ funnel.

where $A o R\left(^{\circ}\right)$ is the angle of repose, $c$ is cohesion $(\mathrm{Pa}), \Phi$ is the particle circularity (-), $C E$ is the equivalent particle diameter $(\mathrm{m}), g$ - gravitational acceleration $\left(\mathrm{m} \cdot \mathrm{s}^{-2}\right), B D$ bulk density $\left(\mathrm{kg} \cdot \mathrm{m}^{-3}\right), A I F$ angle of internal friction $\left(^{\circ}\right)$.

In Fig. 13, a dependence between the $A o R$ and the established criterion from the right side of the equation (2) is shown. A power mathematical model based on the experimental data describing the relationship between the $A o R$ and material properties was developed using a non-linear regression (3). The coefficient of determination was $\mathrm{R}^{2}=0.92$. The differences between the $A o R$ values calculated according to the model created and the $A o R$ values from the experiment are found in Fig. 14. Based on the model, the $A o R$ value for samples of the studied materials with a standard deviation $\mathrm{STDEV}=1.95^{\circ}$ can be calculated. This value is sufficient to correctly characterize the flow of the experimental material. 


\begin{tabular}{lllllll}
\hline Sample & CE $(\mu \mathrm{m})$ & $\Phi(-)$ & $\begin{array}{l}\text { AOR }\left(^{\circ}\right) \\
\pm \text { st. dev }\end{array}$ & $\begin{array}{l}\text { AIF }\left(^{\circ}\right) \\
\pm \text { st. dev }\end{array}$ & $\begin{array}{l}\text { c }(\mathrm{kPa}) \\
\pm \mathrm{st.} \mathrm{dev}\end{array}$ & $\begin{array}{l}\text { BD }\left(\mathrm{kg} . \mathrm{m}^{-3}\right) \\
\pm \mathrm{st.} \mathrm{dev}\end{array}$ \\
\hline Strong flour & 206.2 & 0.791 & $40.18 \pm 1.70$ & $18.40 \pm 3.11$ & $1.325 \pm 0.148$ & $0.722 \pm 0.002$ \\
Semolina & 519.3 & 0.828 & $28.07 \pm 0.18$ & $22.43 \pm 6.49$ & $0.796 \pm 0.174$ & $0.725 \pm 0.001$ \\
Soft flour & 97.7 & 0.849 & $48.58 \pm 2.10$ & $18.37 \pm 2.26$ & $1.597 \pm 0.232$ & $0.632 \pm 0.002$ \\
Sand 0.8-1.2 & 1044 & 0.960 & $26.05 \pm 1.50$ & $36.75 \pm 2.90$ & $0.395 \pm 0.400$ & $1.630 \pm 0.028$ \\
Sand 1.0-1.6 & 1459 & 0.881 & $29.05 \pm 2.00$ & $32.00 \pm 0.00$ & $1.010 \pm 0.000$ & $1.540 \pm 0.000$ \\
GB1 & 152.5 & 0.998 & $25.02 \pm 0.10$ & $20.47 \pm 1.18$ & $0.164 \pm 0.089$ & $1.483 \pm 0.005$ \\
GB2 & 91.71 & 0.997 & $27.57 \pm 0.09$ & $20.97 \pm 0.28$ & $0.239 \pm 0.034$ & $1.447 \pm 0.011$ \\
GB3 & 489.6 & 0.991 & $21.80 \pm 0.20$ & $26.13 \pm 1.02$ & $0.139 \pm 0.090$ & $1.513 \pm 0.006$ \\
GB4 & 338.0 & 0.996 & $25.02 \pm 0.15$ & $23.45 \pm 0.35$ & $0.182 \pm 0.019$ & $1.505 \pm 0.007$ \\
GB5 & 271.0 & 0.997 & $23.43 \pm 0.12$ & $21.67 \pm 0.92$ & $0.165 \pm 0.067$ & $1.500 \pm 0.000$ \\
\hline
\end{tabular}

TABLE 1. Properties of experimental samples (Values of $A o R, A I F, c$ and $B D$ are averaged from three measurements $n=3)$.

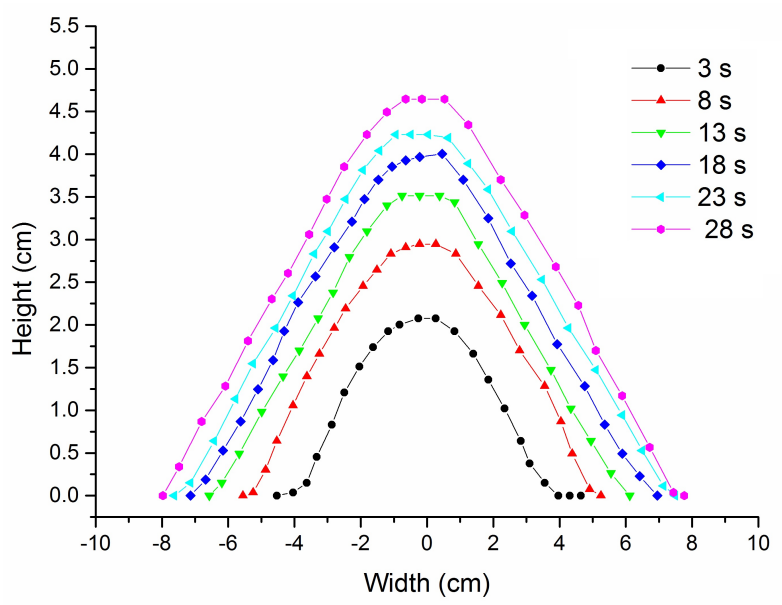

Figure 12. Evolution of $A o R$ during tests with $8 \mathrm{~mm}$ funnel.

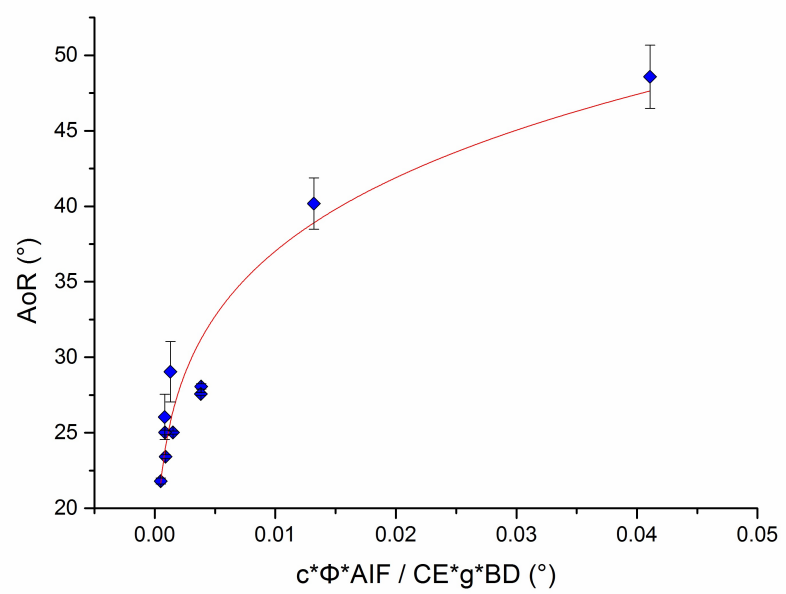

Figure 13. Relationship between $A o R$ and created criteria.

$$
A o R=84.19 \cdot\left(\frac{c \cdot \Phi \cdot A I F}{C E \cdot g \cdot B D}\right)^{0.178}
$$

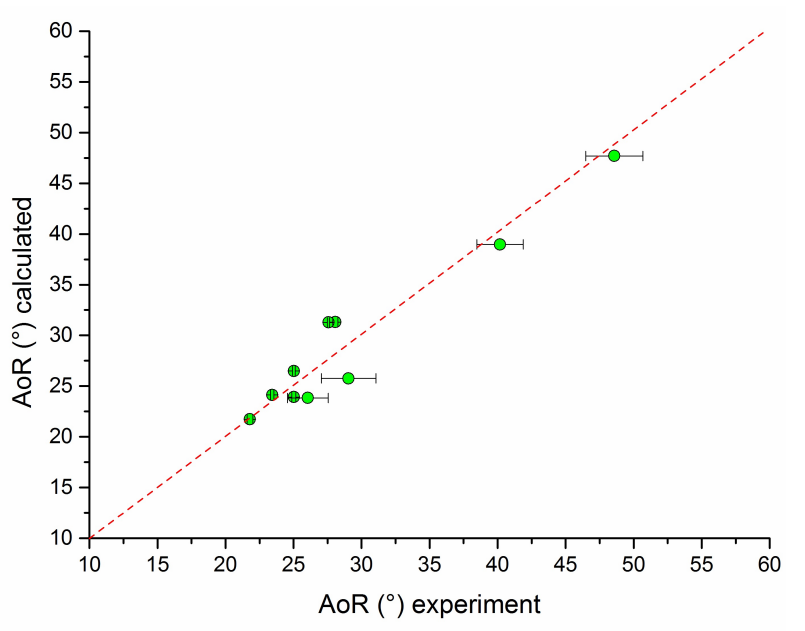

Figure 14. Differences between calculated and experimental $A o R$.

\section{Conclusion}

In this paper, we examined the $A o R$ and its relation to the morphological and rheological properties of the experimental material. The analysed properties of the material had a significant impact on the $A o R$. The highest $A o R$ values were achieved with cohesive flour samples. The $A o R$ increased with increasing cohesion. Spherical particles of glass beads with high $B D$ values had the lowest $A o R$ values, which confirmed their good flow properties. Similarly, larger particles of sand and semolina also had good flow properties. Using the Shear Cell Test, we obtained $A I F$ values that did not show a direct relationship to the $A o R$. The dependence between the cohesion and material flow properties was found. It has been shown that the discharge rate has an influence on the size and shape of the formed pile. Using a dimensional analysis, a mathematical model was developed to determine the $A o R$ based on the properties of the experimental material. Based on this model, it is possible to determine an $A o R$ value with a standard deviation of 
$1.95^{\circ}$, which makes it possible to reliably characterize the flow properties of the experimental material.

\section{LIST OF SYMBOLS}

$c$ Cohesion $[\mathrm{Pa}]$

$d$ Diameter of the pad $[\mathrm{m}]$

$f f_{c}$ Flow function parameter [-]

$g$ Gravitational acceleration $\left[\mathrm{m} \mathrm{s}^{-2}\right]$

AoR Angle of repose $\left[^{\circ}\right]$

$A I F \quad$ Angle of internal friction $\left[^{\circ}\right]$

$B D$ Bulk density $\left[\mathrm{kg} \mathrm{m}^{-3}\right]$

$C E$ Equivalent particle diameter [m]

$H$ Height of the cone [m]

$\Phi \quad$ Particle circularity $[-]$

\section{ACKNOWLEDGEMENTS}

The authors would like to thank Mr. John Peter Blight for language correction.

This article was created with the support of the Ministry of Education, Science, Research and Sport of the Slovak Republic within the Research and Development Operational Programme for the project "University Science Park of STU Bratislava", ITMS 26240220084, co-funded by the European Regional Development Fund.

This work was supported by the Slovak Research and Development Agency under contract No. APVV-18-0348.

The authors wish to acknowledge the Ministry of Education, Science, Research and Sport of the Slovak Republic for the financial support of this research by grant KEGA 016STU-4/2019.

\section{REFERENCES}

[1] G. Xu, P. Lu, M. Li, et al. Investigation on characterization of powder flowability using different testing methods. Experimental Thermal and Fluid Science 92(November 2017):390-401, 2018. DOI:10.1016/j.expthermflusci.2017.11.008

[2] Z. Zatloukal, Z. Šklubalová. Drained angle of freeflowable powders. Particulate Science and Technology 26(6):595-607, 2008. DOI:10.1080/02726350802501369

[3] A. Mehta, G. C. Barker. The dynamics of sand, 1994. DOI:10.1088/0034-4885/57/4/002

[4] H. M. Beakawi Al-Hashemi, O. S. Baghabra Al-Amoudi. A review on the angle of repose of granular materials. Powder Technology 330:397-417, 2018. DOI:10.1016/j.powtec.2018.02.003

[5] D. Geldart, E. Abdullah, A. Hassanpour, et al. Characterization of powder flowability using measurement of angle of repose. China Particuology 4(34):104-107, 2006. DOI:10.1016/s1672-2515(07)60247-4.

[6] H. Hurychová, P. Ondrejček, Z. Šklubalová, et al. The influence of stevia on the flow, shear and compression behavior of sorbitol, a pharmaceutical excipient for direct compression. Pharmaceutical Development and Technology 23(2):125-131, 2018. DOI:10.1080/10837450.2017.1315132

[7] H. Hurychová, M. Kuentz, Z. Šklubalová. Fractal Aspects of Static and Dynamic Flow Properties of Pharmaceutical Excipients. Journal of Pharmaceutical Innovation (iii), 2017. DOI:10.1007/s12247-017-9302-0.
[8] A. Wójcik, P. Klapa, B. Mitka, I. Piech. The use of TLS and UAV methods for measurement of the repose angle of granular materials in terrain conditions. Measurement: Journal of the International Measurement Confederation 146:780-791, 2019. DOI:10.1016/j.measurement.2019.07.015.

[9] A. Wójcik, P. Klapa, B. Mitka, J. Sładek. The use of the photogrammetric method for measurement of the repose angle of granular materials. Measurement: Journal of the International Measurement Confederation 115(July 2017):19-26, 2018. DOI:10.1016/j.measurement.2017.10.005

[10] T. Roessler, A. Katterfeld. Scaling of the angle of repose test and its influence on the calibration of DEM parameters using upscaled particles. Powder Technology 330:58-66, 2018. DOI:10.1016/j.powtec.2018.01.044

[11] V. Hassanzadeh, C. M. Wensrich,

R. Moreno-Atanasio. Elucidation of the role of cohesion in the macroscopic behaviour of coarse particulate systems using DEM. Powder Technology 2019. DOI:10.1016/j.powtec.2019.07.070

[12] T. Roessler, A. Katterfeld. DEM parameter calibration of cohesive bulk materials using a simple angle of repose test. Particuology 45:105-115, 2019. DOI:10.1016/j.partic.2018.08.005

[13] Ž. Trpělková, H. Hurychová, P. Ondrejček, et al. Predicting the Angle of Internal Friction from Simple Dynamic Consolidation Using Lactose Grades as Model. Journal of Pharmaceutical Innovation 2019. DOI:10.1007/s12247-019-09387-3

[14] Z. Guo, X. Chen, H. Liu, et al. Theoretical and experimental investigation on angle of repose of biomass-coal blends. Fuel 116:131-139, 2014. DOI:10.1016/j.fuel.2013.07.098

[15] M. M. De Campos, M. D. C. Ferreira. A comparative analysis of the flow properties between two alumina-based dry powders. Advances in Materials Science and Engineering 2013(December 2013), 2013. DOI:10.1155/2013/519846

[16] M. Rackl, F. E. Grötsch, M. Rusch, J. Fottner. Qualitative and quantitative assessment of 3D-scanned bulk solid heap data. Powder Technology 321:105-118, 2017. DOI:10.1016/j.powtec.2017.08.009.

[17] A. K. Swamy, V. Matolia, G. V. Ramana. Use of angle of repose of aggregates as an indicator of asphalt concrete properties. Construction and Building Materials 168:849857, 2018. DOI:10.1016/j.conbuildmat.2018.02.091.

[18] G. Lumay, F. Boschini, K. Traina, et al. Measuring the flowing properties of powders and grains. Powder Technology 224:19-27, 2012. DOI:10.1016/j.powtec.2012.02.015

[19] W. Wang, J. Zhang, S. Yang, et al. Experimental study on the angle of repose of pulverized coal. Particuology 8(5):482-485, 2010. DOI:10.1016/j.partic.2010.07.008

[20] H. Wei, X. Tang, Y. Ge, et al. Numerical and experimental studies of the effect of iron ore particle shape on repose angle and porosity of a heap. Powder Technology 2019. DOI:10.1016/j.powtec.2019.05.031. 
[21] G. Xu, M. Li, P. Lu. Experimental investigation on flow properties of different biomass and torrefied biomass powders. Biomass and Bioenergy 122(July 2018):63-75, 2019. DOI:10.1016/j.biombioe.2019.01.016.

[22] L. C. dos Santos, R. Condotta, M. d. C. Ferreira. Flow properties of coarse and fine sugar powders. Journal of Food Process Engineering 2018. DOI:10.1111/jfpe.12648.

[23] C. Lanzerstorfer. Dusts from dry off-gas cleaning: comparison of flowability determined by angle of repose and with shear cells. Granular Matter 2017. DOI:10.1007/s10035-017-0745-2.

[24] H. Shi, R. Mohanty, S. Chakravarty, et al. Effect of particle size and cohesion on powder yielding and flow. KONA Powder and Particle Journal 2018(35):226-250, 2018. DOI:10.14356/kona.2018014

[25] J. Zegzulka, D. Gelnar, L. Jezerska, et al. Internal friction angle of metal powders. Metals 2018. DOI: $10.3390 / \operatorname{met} 8040255$
[26] M. Alshafiee, W. H. AlAlaween, D. Markl, et al. A predictive integrated framework based on the radial basis function for the modelling of the flow of pharmaceutical powders. International Journal of Pharmaceutics 2019. DOI:10.1016/j.ijpharm.2019.118542

[27] F. Fulchini, U. Zafar, C. Hare, et al. Relationship between surface area coverage of flow-aids and flowability of cohesive particles. Powder Technology 2017. DOI:10.1016/j.powtec.2017.09.013

[28] M. Šimek, V. Grünwaldová, B. Kratochvíl. Comparison of compression and material properties of differently shaped and sized paracetamols. KONA Powder and Particle Journal 2017. DOI:10.14356/kona.2017003.

[29] Y. Takeuchi, T. Tomita, J. Kuroda, et al. Characterization of mannitol granules and powder: A comparative study using two flowability testers. International Journal of Pharmaceutics 547(1-2):106113, 2018. DOI:10.1016/j.ijpharm.2018.05.061. 